\title{
Critical Analysis of Piaget's Theory and Educational Implications with Special Reference to Language Development
}

American Journal of Education and Learning

Vol. 6, No. 1, 76-85, 2021

e-ISSN:2518-6647

$\checkmark$ updates

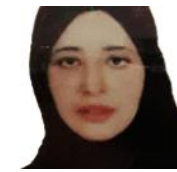

(iD) Jawaher Fahad Alghofaili

The University of Alabama, Birmingham, USA.

Email:jawaheralghofaili@gmail.com Tel:00966564939765

( Corresponding Author)

\section{ABSTRACT}

Jean Piaget's contribution to understanding children's first thought processes cannot be overstated. His theories on child cognitive development is based on their sensory development, egocentric representation, and language have been the prime focus in the paper. Nevertheless, his perspective and theories have been opposed and questioned by some scholars including Whorf (1956),Vygotsky (1962); Vygotsky (1978); Vygotsky (1987) and Baillargeon, Spelke, and Wasserman (1985). While this paper explores and expands on Piaget's theories on the cognitive development of children, it also presents the perspectives of his other critics such as Repacholi and Gopnik (1997) and gives a broad overview of the research and theory of the cognitive development. Lastly, this paper offers strategies and suggestions in applying this knowledge in both the classroom and at home.

Keywords: Cognitive development, Thought, Sensory motor development, Egocentricrepresentation, Language, Strategies.

DOI: $10.20448 / 804.6 .1 .76 .85$

Citation | Jawaher Fahad Alghofaili (2021). Critical Analysis of Piaget's Theory and Educational Implications with Special Reference to Language Development. American Journal of Education and Learning, 6(1): 76-85.

Copyright: This work is licensed under a Creative Commons Attribution 3.0 License

Funding: This study received no specific financial support.

Competing Interests: The author declares that there are no conflicts of interests regarding the publication of this paper.

History: Received: 8 June 2021/ Revised: 21 July 2021/ Accepted: 16 August 2021/ Published: 2 September 2021

Publisher: Online Science Publishing 


\section{Highlights of this paper}

- The paper aims at highlighting the contributions of Piaget and Vygotsky who are generally considered as opponents.

- The difference in their theories lead to two different angles and perspectives concerning the cognitive development among children.

- The theories propounded by them create a basis for curriculum development and pedagogy for effective learning.

\section{INTRODUCTION}

Jean Piaget is widely known for his experiments on children's cognitive development. He observed the intellectual development of his own three children and propounded a theory that is based on the 'stages' that every child goes through in the development of intelligence and formal thought processes. In his book, Play, Dreams, and Imitation in Childhood (1999), Jean Piaget talks about examples of children's first thought processes through sensory motor development and recognizes different cognitive stages based on egocentric representation and language. Piaget expands on his theory of cognitive development in children based on their sensory motor development, egocentric representation, and language. While Piaget's theories and explanations have proved to be useful for decades, they are not without critics and opponents. Many different experiments conducted by scientists have challenged his theories on the development of each of these three concepts sensory motor development, egocentric representation, and language development. In addition to exploring and expanding on Piaget's theories of cognitive development of children, this paper also presents the critical analysis and evidence against his theories and offers strategies on how to apply what we now know about the cognitive development of children. Piaget also believed that cognitive development is a continuous process, and all children, even in different environment and culture around the world, pass through the same series of cognitive development (Babakr, Mohamedamin, \& Kakamad, 2019).

\subsection{Objectives of the Study}

Though there is nothing new regarding the discussions on the theoretical aspects of cognitive development in general and Piaget,Vygostsky and others in particular, the essence, application and follow up is always contextual, and debatable. Thus, the focus is mainly on the relevance of stage theory proposed by Piaget and an entirely different stand taken by Vygostsky, Whorf and many others. The conclusions are likely to open up new room for further discussions.

\subsection{Research Gap}

Nearly all the researches on cognitive development have focused on stage theory of Piaget and Vygotsky' socio-cultural theory, but theory of Benjamin Lee Whorf's about language, hypotheses suggested by him, has been neglected. In addition, Baillargeon et al. (1985) theory of Object permanence (in five-month-old infants) has not much been leveled against Piaget. The work of Repacholi and Gopnik (1997) has not been given much attention which talks about Early reasoning about desires: Evidence from 14- and 18-month-olds. This study has dealt with these theories to arrive at more fruitful conclusions.

\subsection{Sensory Motor Development}

Piaget suggested that all the children, go through the same stages: sensorimotor, preoperational, concrete dealing (Moreno, 2010). During the process of moving through one stage to the next, children's cognitive ability accordingly change (Sigelman \& Rider, 2012). 
According to Piaget (1999) the sensory motor skills of children ages 0-2 years of age are not developed that much by which they understand object permanence or spatial perception in reference to external factors. Piaget argues that children at the ages of $0-2$ years old must rely on the reaction of an object in relation to their own position in the given environment based on previous schemas and repeated actions. His theory propounds children had a limited use of their sensory motor skills to function in ways that required them to use perceptual constancy of size and shape of objects, as well as their permanence in relation to themselves. The scientist believed that children before the ages of nine months were the same in their levels of perceptive sensory motor skills. In order to create such a theory, he conducted experiments in which he dropped a toy out of sight in front of his seven-month old daughter. She had reached for the toy until it disappeared and then stopped grasping for it. He concluded that she did not recognize object permanence because she did not consider that the toy might exist outside of her relative perception (Piaget, 1999). Piaget conducted a similar study for a nine-month old infant. He showed the infant a toy and then hid it under a cloth. This time, the infant was aware that the toy was beneath the cloth and pulled the cloth off. Piaget concluded that before the ages of nine months old, children did not develop perceptive skills and object permanence in their sensory motor development. However, Piaget did not take into consideration that not all the skill levels of children were alike at the same age and could be altered by external factors as well as deeper indications of their object recognition. Hence, it must be noted that no theory is beyond opposition or criticism.

In this connection, another contemporary researcher, Baillargeon, Spelke, and Wasserman (1985) who contributed greatly to the theories of Monastersky (2000) arrived at different conclusions regarding sensory motor skills of the children. Baillargeon et al. (1985) thought that Piaget's theory on the stages of sensory motor development in children was not entirely representative. She found that children of around five months old could recognize objects that were absent from their point of view (Baillargeon. et al., 1985). She conducted a study in which five month old children were given toys and then hidden from sight. Instead of observing the infants' physical patterns such as grasping or reaching for the toy, Baillargeon et al. (1985) used their eye movements of indicators to the intent of their purposes behind their motions. She discovered that even with the toy out of sight, the eye movement of five-month old infants followed the toy with what appeared to be anticipation of its reveal Baillargeon. et al. (1985). The scientist also measured how long each infant gazed at the object and the situation it was in when it disappeared. She stated that infants are much more advanced in object permanence than Piaget originally thought based on their eye movements. Young infants are aware of their surroundings have sophisticated explanations for those surroundings. Further, Baillargeon et al. (1985) also conducted experiments where children as young as ten weeks old gazed longer at objects that disappeared, suggesting greater awareness and depth to their sensory motor skills than was previously believed. She now supports the idea that children are born with some innate knowledge of how the world works, such as the notion that objects exist permanently (Monastersky, 2000).

Bower (1982) and Harris (1983) also confronted saying that some children develop object-permanence earlier than Piaget thought. Therefore, the stages may be inaccurate or just wrong. The child development community did not unanimously accept this conclusion and researchers such as Huttenlocher and Clifton (as cited in Monastersky (2000)) believe that those explanations go too far to describe a rudimentary process and that Baillargeon has placed too much stock on the precursor concepts of object permanence.

The debate on when children are cognizant of object permanence is continued to be examined by Moore, Borton, and Darby (1978) who offer an alternative explanation. Through experiments by Moore et al. (1978) with babies 10-14 months in age, they come the conclusion that babies at this state do indeed have incomplete object permanence Moore et al. (1978). They offer the idea that babies are born with the ability to know about how the world works. However these theories are often inaccurate and incorrect. What babies actually do is test out these 
theories in everyday life in order to confirm or adjust their models of the world (Moore et al., 1978). Meltzoff describes a baby as “a scientist, who can’t leave the laboratory at night,” (as cited by Monastersky (2000)).

This debate refutes and confirms some of Piaget's theories on child's' conceptual understanding of object permanence. From the above experiments, we can conclude that babies are not completely oblivious to the idea of objects existing outside their line of vision. However, this understanding is elementary and without solid conviction. Babies spend their childhoods testing out and refining these theories of the world through their interactions with others and with the physical world.

\subsection{Egocentric Representation}

Children's understanding and perception of object permanence is not the only notion that has been disputed among the child development theorists. During Piaget's research, he based most of his work on the fundamental notion that children had a tendency for egocentric activity ranging from the age of two years to seven years old (Piaget, 1999). A few of his cognitive developmental theories of children at this age assert that they are egocentric in regards to their play and social cooperation. According to Piaget (1999), this egocentric tendency is manifested in children between these ages of 0-7 because they more likely to play in isolation and do not cooperate with the feelings of others. Also, he claims that children at this age do not consider intentions of others or consider their points of view (Piaget, 1999).

In one observation, Piaget noted a girl at 21 months who described objects and people in the room as they appeared before her. She would spend time identifying to everyone who came in the room different people and things as she saw them. However, even when she was alone, the girl described the objects to herself, which indicated egocentrism. Piaget believed that through the verbal exchanges the child had with herself as well as her family, she was somewhere between communicating with the adults in her life as well as remaining isolated in her resolve to do so. Many scientists have disputed Piaget's claims that children at ages as young as two years old are egocentric. Repacholi and Gopnik (1997) conducted experiments on children at 14 and 18-months old where they gave the infants two choices of broccoli and crackers. The experimenter showed the children her face when she ate a piece of broccoli and a cracker and made a happy face or a disgusted face, depending on what she ate. Afterwards, the experimenter asked the children if they could share the food with her. The 18-month olds almost always gave the experimenter broccoli because she had indicated before that this was the food that made her happy by smiling while she ate it. However, the 18-month olds did not choose the broccoli for themselves. This showed that they were capable of perceiving her feelings as valid and recognizing her needs, regardless of which food they preferred (Repacholi \& Gopnik, 1997). The 14-months old always gave her crackers, indicating that perhaps they were not yet aware of the implications of external factors.

According to Piaget (1999) children are illogical and irrational with no apparent intentions present in reactions such as cause and effect. Repacholi and Gopnik (1997) disproved Piaget's theories through this experiment by utilizing the children's sensory motor skills and egocentric representation when it came to understanding the needs of others Repacholi and Gopnik (1997). Badakar et al. (2017) and Asokan, Surendran, Asokan, and Nuvvula (2014) explored the relevance of Piaget's cognitive principles among parented and orphan children, and found that the characteristic features explained by Piaget were present in most of the children between ages of 4 and 7 years.

\subsection{Children and Language}

As mentioned earlier that Piaget (1999) is of the opinion that thought precedes language. He believes that without thought, language is not possible. Piaget also believes that the schemas in children's lives must be present 
before the thought can manifest itself into a language (Piaget, 1999). He supports the idea that thought drives language. In the examples given throughout Part III of the book Play, Dreams and Imitation in Childhood, Piaget (1999) assesses that the language skills of children aged 0-11. These children are evaluated in situations in which they are beginning to associate schemas with words that they use to form language. Piaget (1999) believes that these schemas result in the pre-concept of language that supports his theory that the latter cannot exist without the former. This is demonstrated in examples throughout Part III of the book that followed the way children perceive new experiences, use words to apply new objects to their experiences, and traces the thought process they go through when they shift from one stage to another in Piaget's cognitive development theory.

Piaget (1999) cites many examples of children who use schemas to support his argument on language development. One example is when he observes his own child, a girl, who was aged one year, six months, and thirteen days. This child had used the word "panana" as a replacement for an experience she had (Piaget, 1999). At the early stages of Piaget's theory of development, the child was beginning to conceptualize her experiences. She had recognized an experience with her grandfather, one in which she had wanted to repeat. Instead of calling out the name of her grandfather or rather his title, she used the word "panana" in reference to him as well as any other objects she had associated with his experience with her. She used this word as a replacement word for experiences that were all grouped together into something she wanted to verbalize. The child did not make distinctions between the experiences, but rather spoke of them generally and without differentiation. This meant that if her grandfather was going to buy her something or if she was in an environment that placed her somewhere she had been with her grandfather, she would say "panana" as a collective term used to describe what she was referring to Piaget (1999). This supports Piaget's theory of language because he believes that without the pre-concept stage, this child would not have the language skills needed to say "panana". Piaget believed that she did not formulate her thoughts based on the language, but rather formed her words (in this case, one without any kind of association to the word "grandfather") as a bridge between the adults around her and the experiences she wanted to share.

However, the theory that language comes as a result of thought has been discounted by many scientific and linguistic studies across many academic circles. Whorf (1956), a linguist, argued that language determined thought processes. Whorf is quite popular for his theory of linguistic relativity which postulates that language influences thought. He has been credited with experimenting "Sapir-Whorf hypothesis", named after him and his mentor Edward Sapir. His main contributions relate to different linguistic systems affected the thought systems and habitual behaviour of language users. As a result, speakers of "all kinds of languages have different thought processes from one another" (Holmes \& Wolff, 2011). This is believed because the role language has for shaping cognitive development is so strong; it basically overcomes any conceptual capabilities that may have previously existed. This is further supported by evidence that "infants can be accounted for experiencing advanced thinking capabilities even though language is not present" (Holmes \& Wolff, 2011).

Daniel Slobin, a linguistics professor, discussed the "thinking for speaking" experience in which thought processes occurred according to how they were to be spoken (as cited in Holmes and Wolff (2011)). According to this theory, people's attention patterns as well as their memories are considered when observing how they shift according to the way they verbalize them (Holmes \& Wolff, 2011). A study conducted by Anna Papafragou (as cited in Holmes and Wolff (2011)) supports this theory through some experiments where asked native speakers of English and Greek to watch the motion of events. When the subjects of the study were watching it aimlessly, the eye movement patterns were the same. The native speakers did not differentiate in patterns when they did not perceive to speak about the events. However, when the subjects of the study were told once again to observe the events, but this time with the intention of responding verbally with what they saw, the eye movement patterns were 
markedly different. The Greek native speakers observed the path more closely than the manner of the events. The English speakers were different. They viewed the pattern of the events as opposite to the Greek speakers. This meant that the speakers' mind processes conformed to their ability to describe the events through language specific patterns (Holmes \& Wolff, 2011). The speakers considered the events with the intention of speaking on what they saw and so this shifted the way they interpreted the event. In sum, one's language orients their view on life and shapes their internal interpretations of external events.

As one of Piaget's opponent, Vygotsky (1978) is also credited with the conceiving theories of cognitive development that involve egocentric speech to engage in social interactions. Both theories share similar ideas that each child should participate actively in his or her own learning. Besides, Vygotsky and Piaget theories acknowledge social relationships as part of the development. However, the theories view the roles of social relationships differently. Vygotsky claimed that social relationships can be an indicator of learning and development. Thus, there appears an involvement appears between at least two individuals (peers). The differences may include different ages (between a child and an adult) or different competences (a young student and an adult or a teacher). Vygotsky's theory highlighted social relationships between a child and an adult or a more competent person provide wide opportunity for the child to learn and develop. In other words, learning can't take place in isolation. Rather a more experienced and knowledgeable person is required to develop the cognition and enhance learning. In other words, the child internalizes what they see and learn from the social life (Lourenço, 2012).

No discussion on language and cognitive development can be complete without (Chomsky, 1959). Beginning with Chomsky (1959), the discipline as a whole has become more holistic in nature which enables theorists and scholars to grasp and undertake psychological studies pertaining to developmental capacities of one's mind. To be more precise, the process of language learning is not a random phenomenon. However, it is conceived that humans tend to possess the Language Acquisition Device (LAD).

Psycholinguistics assumes that a child is born with the biological ability that helps him to acquire language. It is believed that a child constructs the native language grammar without the help of others. But, it is not clear at all as to how the first and second languages are acquired. Chomsky contended that a child knows how to frame a sentence, but they do not actually know the reasons (Ormond, 2012).

In this connection, Hockett (1966) said that human beings acquire comprehension of language through nothing but language acquisition. This enables them to reproduce this knowledge while they converse with others. However, it can't be categorically discussed as to what is the actual difference between the learning of first and second language. Chomsky, however, posited that native speakers are born with an innate ability to develop language because they are born with a cognitive sense of language, as cited by Radford (2004) when the later confirmed that any native speaker of a language can be said to know the grammar of his or her native language. All developmentally normal English speakers are at least moderately successful in following the rules of language acquisition. Chomsky points out towards certain patterns in grammar that can't be learnt by only watching and listening. They have to eat engaged in other activities. He indicated that they must possess some innate capacity for language independence. Chomsky's view contributes to a natavistic approach confirming that there are some cognitive abilities are possessed by humans from the birth that enable them acquire certain skills (Slobin, 2004).

Piaget initially associated social relationships as a moral relativism between two individuals who uphold equality, collaboration, and mutual respect. The theory does not take into account the intellectual development from the interactions with other individuals, as Piagetian believes that a child can learn independently and his/ her developmental stages occur progressively along with the internal process. Piaget considered that social relationships do not play significant role toward a child's development. The theory perceived individuals as 
independent or autonomous subjects with internal abilities to accommodate and assimilate new concepts with or without guidance from adult; thus, external factors including social relationships do not contribute specific impacts to the development (Lourenço, 2012).

\section{FINDINGS}

The study explored that despite the fact that Piaget's studies on stages of cognitive development were pioneering in nature, there are certain limitations. one of them are: the study/observation of Piaget has only relied on his children while theory of individual difference in psychology can never be underestimated. Piaget has always been compared and constrasted with Vygostsky. But, this study has included the perspectives of Whorf (1956), Baillargeon et al. (1985) and Repacholi and Gopnik (1997) which gives a broad overview of the research and theory of the cognitive development.

\section{CONCLUSIONS}

It is concluded that despite the opposition and criticism mentioned and discussed above, there are many other points which became the point of difference among scholars and scientists. Piaget's theory seems to support at a point that reaching the formal operational stage is the ultimate goal of development. However, it is not clearly put forth if all of us completely accomplish the developmental tasks during formal operations. It has been noted that in many adults' cases they may struggle to think abstractly about situations, falling back on more concrete operational ways of thinking (Hopkins, 2011). The author criticized Piaget's theory saying that the theory underestimated children's abilities. It was thought of that most researchers are in agreement that children have many of the abilities at an earlier age than Piaget suspected. Theory of mind research has found that a 4-5 year old child may possess a considerably good understanding of their own mental processes as well as those of other people, said (Korkmaz, 2011). For instance, children of this age have some ability to take the perspective of another person, meaning they are far less egocentric than Piaget believed (Hopkins, 2011). In addition, McLeod (2018) studied about development of self evaluation skills in relation to Piaget's cognitive development theory that children go through four different stages of mental development. The author not only deals with the understanding how children acquire knowledge, but also on understanding of intelligence. Cherry (2018) also worked on the relevance of 4 Stages of Cognitive Development. In a recent study, it was admitted when conceptualizing cognitive development, one cannot neglect the pioneering work of Jean Piaget who suggested that when young infants experience an event, they process new information by creating a good balance between assimilation and accommodation (Malik \& Marwaha, 2020).

\subsection{Applications in the Classroom}

Despite some criticism, Piaget is a true champion of cognitive theories. The main application of his stage theory is curriculum design as a curriculum designer or text book writer selects topics and material according to the stage wise cognitive development. Regardless of dispute on the priority of thought (content) or languages (mode of expression), Piaget's theory remains valid and significant, however, other theorists opinion can also be considered to create a curricular balance for evolution of a compatible pedagogy.

As Piaget postulated that humans are active meaning-makers who don't need a readymade knowledge to receive, but they need a setting in which they can create a 'construct'. As an educator, learning more about children's cognitive developmental skills is important because it can affect their learning. It is important to learn Piaget's theory of cognitive development, because it can be used to better understand children thinking and 
therefore to design activities that can help determine the basic level of mental capabilities that their students' have. However, children have been shown to be a lot more sophisticated than Piaget had believed, because they can recognize the desires of others, understand cause and effect, and have some understanding of object permanence. This means that they are much more likely to be advanced at interpreting information. Therefore, it is important for teachers to know new theories, which when combined with Piaget, can be used to create activities that help improve the mental abilities of children.

The implications for application of Piaget's theory are mainly linked to the classroom setting: children should be given freedom to explore the possibilities of their imagination, because as Piaget says, "one who attains a certain knowledge through free investigation and spontaneous effort is more likely to retain it”(Wadsworth, 2004). Play groups that encourage children to play dress up or have imaginary friends can be a lot more productive as a tool for developing their thinking than sitting down and teaching a child academic work (Vygotsky, 1978). This is because in play groups children mimic life by playing out real life situations in a fantasy world. They learn to creatively problem solve in situations that they invented and display reasoning skills for their own little worlds (Nilsson \& Ferholt, 2014). For example, when children use common objects like bowls as drums or play house with classroom items, they are displaying awareness about real-life situations. This is a way for them to not only understand how people around them live, but also a way to learn that they are also part of this environment (Vygotsky, 1978).

Play groups also require children to interact socially and use social-language. This is important because "a child figures out the rules of the language from his or her social-language experience” (Wadsworth, 2004). All children between the ages of two to seven years use both egocentric and social speech. However younger children, from ages two to four, tend to use more egocentric speech than older children, from ages four to seven, who tend to use more socialized speech. When teachers require children to engage in play groups it helps them to move from egocentric speech towards social-language and leads to an improvement in their language.

From these recommendations, we can incorporate general activities, which are based on Piaget's cognitive developmental theory teacher should support and provide a classroom that nurtures and facilitates cooperative learning, positive peer relations and character development, though the activities may vary among age groups where the essential constructivists theory is applied, so that the outcome is the same. Teachers must facilitate interact, cooperation and the desire to learn through an atmosphere of respect.

It is suggested that the concerned teachers should better focus on more than just making sure that the children receive physical activities. They should also provide children the opportunity as much as possible to climb trees or go on adventures that require them to discover things and come to new conclusions. However, classroom experiments are also important. Piaget is of the view that a child also constructs "intellectual power intelligence" (DeVries \& Zan, 1994). Therefore, a teacher should try to promote experimental attitudes among children to promote learning. In addition, children between the ages of two to seven years old require "egocentric representative activities" (Piaget, 1951/1962). These activities develop in two stages: pre-conceptual thought and intuitive thought. The pre-conceptual thought stage is between the ages of two to four years and the best activities of this stage are symbolic games as mentioned earlier. Older children between the ages of four to seven years are in the intuitive thought stage and can engage in activities of higher-level symbolic play such as play-acting. At this stage, it is imperative that an educator introduce problem-solving activities such building blocks and math problems. According to Piaget (1951/1962), children at this stage are now capable of problem solution thinking.

The variety of activities presented, as well as the theory behind them, confirm the importance for a teacher to understand which Piaget cognitive stage his or her students are in and provide activities that are appropriate for 
that stage. The ultimate goal of all educational activities is to enrich the lives of the students and these recommendations are aimed to maximize the potential development of each stage.

In sum, following activities can be incorporated in early childhood or elementary education, accordingly to Piaget's theories:

In order to catch attention of the learners, the teachers should better use concrete props and visual aids as per the need. Instructions should relatively be short alongside actions as well as words. In addition, no one should expect the students 'ideas match someone else's point of view. So, students' perspectives can't be ignored. It is also essential to take care of multiple answers and responses on a single question or action, to deal with the language teaching situation. Students usually expect everyone to understand words they have differently thought about. Their ideas must be rewarded. Exercises like building blocks should be utilized for more complex skills like reading comprehension. Last but not least, the teachers should provide varied experiences to lay a basis for concept learning in general and language learning in particular.

\section{REFERENCES}

Asokan, S., Surendran, S., Asokan, S., \& Nuvvula, S. (2014). Relevance of Piaget's cognitive principles among 4-7 years old children: A descriptive cross-sectional study. Journal of Indian Society of Pedodontics and Preventive Dentistry, 32(4), 292296. Available at: https://doi.org/10.4103/0970-4388.140947.

Babakr, Z. H., Mohamedamin, P., \& Kakamad, K. (2019). Piaget's cognitive developmental theory: Critical review. Education Quarterly Reviews, 2(3), 517-524. Available at: https://doi.org/10.31014/aior.1993.02.03.84.

Badakar, C. M., Thakkar, P. J., Hugar, S. M., Kukreja, P., Assudani, H. G., \& Gokhale, N. (2017). Evaluation of the relevance of Piaget's cognitive principles among parented and orphan children in Belagavi City, Karnataka, India: A comparative study. International journal of clinical pediatric dentistry, 10(4), 346-350. Available at: https://doi.org/10.5005/jpjournals-10005-1463.

Baillargeon, R., Spelke, E. S., \& Wasserman, S. (1985). Object permanence in five-month-old infants. Cognition, 20(3), $191-208$.

Baillargeon., R., Spelke, E. S., \& Wasserman, S. (1985). Object permanence in five-month-old infants. Cognition, 20(3), 191-208. Available at: https://doi.org/10.1016/0010-0277(85)90008-3.

Bower, T. G. R. (1982). Development in infancy. San Francisco: Freeman W. H.

Cherry, K. (2018). Piaget's theory: The 4 stages of cognitive development background and key concepts of Piaget's theory. 2018. Retrieved from: https://www.verywellmind.com/piagets-stages-of-cognitive development-2795457 [Accessed May 8, 2018 ]. V.

Chomsky, N. (1959). A review of B. F. Skinner's verbal behavior. Lan Guage, 35, 26-57. Available at: 10.2307/411334.

DeVries, R., \& Zan, B. (1994). Moral classrooms, moral children: Creating a constructivist atmosphere in early education. New York: Teachers College Press.

Harris, P. L. (1983). Infant cognition. In M. M. Haith \& J. J. Campos (Eds.), Handbook of child psychology: Infancy and developmentalpsychobiology (Vol. 2, pp. 689-782). New York: Wiley.

Hockett, C. F. (1966). What Algonquian is really like. International Journal of American Linguistics, 32(1), 59-73. Available at: https://doi.org/10.1086/464880.

Holmes, K. J., \& Wolff, P. (2011). Simulating realism in language comprehension. In L. Carlson, C. Hölscher, T. Shipley (Eds.). Paper presented at the Proceedings of the 33rd Annual Conference of the Cognitive Science Society (pp. 2884-2889). Austin, TX: Cognitive Science Society.

Hopkins, J. (2011). The enduring influence of Jean Piaget: Association for Psychological Science. 
Korkmaz, B. (2011). Theory of mind and neurodevelopmental disorders of childhood. Pediatric Research, 69(8), 101-108. Available at: https://doi.org/10.1203/pdr.obo13e318212c177.

Lourenço, O. (2012). Piaget and Vygotsky: Many resemblances, and a crucial difference. New Ideas in Psychology, 30(3), 281-295. Available at: https://doi.org/10.1016/j.newideapsych.2011.12.006.

Malik, F., \& Marwaha, R. (2020). Cognitive Development. [Updated 2020 Aug 18]. In: StatPearls [Internet]. Treasure Island: Stat Pearls Publishing.

McLeod, S. (2018). Jean Piaget's theory of cognitive development. Pschology Today, 1-4.

Monastersky, R. (2000). A new round of research rattles old ideas of how infants interpret the world. Chronicle of Higher Education, 46(29), A22-24.

Moore, M. K., Borton, R., \& Darby, B. L. (1978). Visual tracking in young infants: Evidence for object identity or object permanence? Journal of Experimental Child Psychology, 25(2), 183-198. Available at: https://doi.org/10.1016/00220965(78)90076-0.

Moreno, R. (2010). Educational psychology. Hoboken, NJ: John Wiley \& Sons, Inc.

Nilsson, M., \& Ferholt, B. (2014). Vygotsky's theories of play, imagination and creativity in current practice: Gunilla Lindqvist's" creative pedagogy of play" in US kindergartens and Swedish Reggio-Emilia inspired preschools. Perspectiva, 32(3), 919950 .

Ormond, J. E. (2012). Long term memory II: The nature of knowledge. In Human Learning (pp. 224). Boston: Pearson.

Piaget, J. (1951/1962). Play, dreams and imitation in childhood (translation by Gattegno S. \& Hodgon F.M.). London: Routledge \& Kegan Paul.

Piaget, J. (1999). Play, dreams and imitation in childhood. New York: Psychology Press.

Radford, A. (2004). English syntax: An introduction: Cambridge University Press.

Repacholi, B. M., \& Gopnik, A. (1997). Early reasoning about desires: Evidence from 14-and 18-month-olds. Developmental Psychology, 33(1), 12-21. Available at: https://doi.org/10.1037/0012-1649.33.1.12.

Sigelman, C. K., \& Rider, E. A. (2012). Life-Span Human development. Belmont, USA: Wadsworth, Cengage Learning.

Slobin, D. I. (2004). Cognitive prerequisites for the acquisition of grammar. In B. C. Whorf, B.L. Science and linguistics" first published in 1940 in MIT Technology Review (42:229-31); reprinted in Carroll (1956:212-214).

Vygotsky, L. S. (1962). Thought and language. Cambridge MA: MIT Press.

Vygotsky, L. S. (1978). Mind in society: The development of higher psychological processes. Cambridge, MA: Harvard University Press. Vygotsky..., L. S. (1987). Thinking and speech. In R.W. Rieber \& A.S. Carton (Eds.), The collected works of L.S. Vygotsky, Volume 1: Problems of general psychology (pp. 239-285). New York: Plenum Press.

Wadsworth, B. J. (2004). Piaget's theory of cognition and affective development. Boston, MA: AUyn \& Bacon.

Whorf, B. L. (1956). Science and linguisitic. In J. B. Carroll (Ed.), Language,thought, and reality: Selected writings of Benjamin Lee Whorf (pp. 375). Cambridge, MA: MIT Press. 